\title{
Developments in Xerography:
}

\section{Copyflo, Electrostatic Prints, and O-P Books}

$\mathrm{T}_{\mathrm{t}}^{\mathrm{n}}$ RADE NAMES are often useful in distinguishing a product of a particular company from a similar product of a different company. The need for this kind of differentiation, however, obscures similarities or even conceals identities, and we find ourselves talking about individuals of the same species as if they were genera. This has been especially true in the field of documentary reproduction where, in one instance, a single process masquerades under at least seventeen different trade names. ${ }^{1}$ A new manifestation of this is beginning in advertisements for reproductions variously called "Copyflo" prints, "Electrostatic Prints" and "O-P Books." We are not dealing here with three different processes: all three are simply xerographic prints from microfilm produced by means of an automatic, continuous microfilm enlarger called "Xerox-Copyflo."2 The purpose of this article is to describe this particular method of reproduction, to discuss some of its advantages and limitations, and to provide other information of a kind which may help librarians, archivists, and other documentalists to employ this new method effectively and economically.

Xerography is not new to the library world. Shortly after Xerox ${ }^{3}$ copying

1 W. R. Hawken, "The Diffusion Transfer Process," MS. Paper read at the meeting of the Copying Methods Section, Resources and Technical Services Division, America Library Association, 77th Annual Conference, San Francisco, July 13-19, 1958.

2 Registered trade-mark of Haloid-Xerox, Inc.

3 Registered trade-mark of Haloid-Xerox, Inc.

Mr. Hawken is Head, Library Photographic Service, University of California, Berkeley. equipment became commercially available (1950), Hodgson described the process in detail and suggested a number of possible library uses. ${ }^{4}$ By 1953 several libraries had acquired Xerox equipment for reproducing catalog cards from typed copy or from LC proof sheets. ${ }^{5,6}$ In other library applications it has proven its value as a mean of producing paper masters for offset printing. ${ }^{7}$ Its use in the production of association bulletins ${ }^{8}$ and an abstract bulletin ${ }^{9}$ has been described.

In the new method called Xerox Copyflo, the basic principles are no different from those employed in simpler forms of xerographic copying. A grounded selenium plate possessing special photoconductive properties is exposed to a corona discharge in the dark which imparts a uniform electrostatic charge to its surface. When the image of a document is projected through a lens onto the surface of this charged plate, light reflected from the white background areas causes the charge to be dissipated to ground, while in the image areas which have not reflected light the charge remains, thus creating what is called an "electrostatic latent image." The plate is then cascaded with a black powder

4 J. G. Hodgson, The Use of Xerography in Libraries (Fort Collins: Colorado A. \& M. College, 1952).

B J. G. Hodgson, Xerography in Reproductive Process for Libraries (Fort Collins: Colorado A. \& M. College, 1953).

J; H. Dawson, "Xerography in Card Reproduction,"; $C R L, \mathrm{XV}(1954), 57-60$.

B. H. Weil, "Xerography: Dry Photographic Copying," in Information Processing Equipment, M. P. Doss, ed. (New York: Reinhold, 1955), pp. 105-14. 8 J. G. Hodgson, "The Use of Xerography for Association Bulletins," Library Periodicals Round Table News Letter, I (1954), 6-7.

News Letter Wright and R. C. Gremling, "Abstract Bulletin Xerographic Short Cut," Special Libraries, XLV (1954), 250-51. 
which clings by electrostatic attraction to the charged image areas, rendering the image visible. This powder image is then transferred, again by electrostatic attraction, to a sheet of plain white paper and is then fused to the paper by heat to form the final copy. In ordinary xerographic copying the successive steps are performed manually. "Copyflo" is simply the name given to a machine which performs all of these operations rapidly, automatically, continuously, and at a much lower per-print cost than has been hitherto possible by other photographic methods.

There are three models of Copyflo equipment available, one of which reproduces only from microfilm, another only from loose-sheet originals, and a third which combines both of these functions. Copyflo Model 1 reproduces single positive copies continuously from $35 \mathrm{~mm}$. or $16 \mathrm{~mm}$. roll microfilm, positive or negative (but not intermixed), perforated or unperforated. The enlargement range is from seven to twenty-four diameters in fifteen steps. Copyflo Model 2 reproduces single copies of opaque or translucent originals at ratios from 46 per cent to 200 per cent of original size. The maximum width document which can be reproduced is twenty-four inches (reduced to 46 per cent of original size in copying). Copyflo Model 3 combines all of the features of Models $\mathrm{I}$ and 2 and is interchangeable from microfilm to original document operation and vice versa. The rate of output for all three models is the same-twenty linear feet of paper per minute.

When Copyflo equipment first became available in 1956, some of the larger commercial microfilm service companies acquired Model 1 machines to provide enlargements from microfilm at rates which were substantially lower than those for the silver halide photoprints formerly supplied. By using the services of one such commercial firm, the John
Crerar, Newberry, and University of Chicago libraries began supplying such enlargements to clients of their photoduplication services. The Newberry Library's experience with this method prompted Ben C. Bowman, assistant librarian at Newberry, to suggest this method as a solution to the bad-paper book problem. He cited as an example the complete reproduction of a 110-page book by this process at a cost of less than five dollars, and suggested ways in which a wider and better coordinated use of this method might benefit all libraries faced with the bad-paper book problem. ${ }^{10}$

In 1957 the Library of Congress and the National Library of Medicine acquired Copyflo machines for the production of photocopies of materials in their collections.

In October 1957, University Microfilms, Inc., announced that they had acquired a Copyflo machine and could supply enlargements from their extensive collection of master negatives, or from microfilms sent to them for printing. ${ }^{11}$ Half-size $\left(51 / 2^{\prime \prime} \times \quad 81 / 2^{\prime \prime}\right)$ enlargements from their file of master negatives of doctoral dissertations were offered at a flat rate of four cents per page. ${ }^{12}$ In 1958, University Microfilms, Inc., offered a further service called "O-P Books," or "OPb." By working out agreements with a number of publishing houses in the United States, copies of out-of-print books are supplied in the form of enlargements produced from microfilm by means of Copyflo equipment at a flat rate of $31 / 2$ cents per page for octavo-size pages measuring $61 / 2$ × $93 / 4$ inches or less. This price includes a soft paper binding. ${ }^{13}$ Wagman has pointed

10 Ben C. Bowman, "Xerography, Possible Solution to the Bad-Paper Book Problem," CRL, XIX (1958), $185-86$.

11 "Xerography Comes to U-M-'Electrostatic' Printing from Film," Microcosm, III (1957), 1-2.

12 E B Power "Printing' in Editions of One," Microcosm, III (1957), 4.

${ }^{13}$ O-P Books: Cumulative List as of Jan. 1959. (Ann Arbor, Mich.: University Microfilms, Inc., 1959.) 
out that in many instances the cost of reproducing out-of-print books by this method in editions-of-one will not exceed the purchase price of a volume on the second-hand book market where there is a competing demand. ${ }^{14}$

In 1958, the Recordak Corporation, one of the first commercial firms to acquire Copyflo equipment, began to advertise "Electrostatic Prints" in library publications for making low-cost full size reproductions of books.

The various announcements and advertisements, particularly those stressing the unusually low cost of the prints produced, naturally attracted considerable interest on the part of librarians. This interest was heightened by the appearance of an advertisement for "O-P Books" which included a testimonial by Verner Clapp, President of the Council on Library Resources, in which he was quoted as follows: "A magnificent achievement-O-P Books solves the outof-print book problem."15

It is in the nature of advertisements to state in very brief, attention-getting terms what a particular machine or process can do, and any examples of quality or cost are usually taken from ideal instances. Ascertaining what the limitations of a process might be, what things it specifically cannot do, or what the costs might be under average rather than optimum conditions is usually much more difficult. In the case of Copyflo, a number of limitations exist which, for certain types of materials, will rule it out as a possible method of reproduction, whether from existing microfilms or from original documents. The effective use of the Copyflo method as a library tool and any evaluation of its effectiveness in solving the out-of-print book or other documentary reproduction

14 F. H. Wagman, "The Copyfio Process and the Problem of Out-of-Print and Deteriorating Book Stocks," Microcosm, IV (1958), 1-2

${ }_{10} C R L$, XIX (May, 1958), inside cover. This ad vertisement has also appeared in other publications. problems must begin with an understanding of certain interrelated physical, technical, and economic factors which impose limits on its usefulness.

PHYSICAL FACTORS

Size

In Copyflo printing, a roll of microfilm $16 \mathrm{~mm}$. or $35 \mathrm{~mm}$. in width becomes a roll of enlarged paper prints ranging in size from $41 / 2$ to 11 inches in width. ${ }^{16}$ The format of the pages and frames on the completed roll of paper prints is exactly that of the microfilm. The size of the original documents and the format framing, spacing, and alignment of the successive images are therefore factors which must be considered in the production of microfilms for subsequent printing with Copyflo equipment.

\section{Format}

Documents may be filmed in any one of the four formats shown in Figure 1. The selection of the best filming position will be determined by the size of the original and the size of the reproduction desired, always keeping in mind that dimension " $A$ " cannot exceed 11 inches in the final print.

Position $1 \mathrm{~A}$. Single pages 11 inches in width and of any length can be reproduced full size by Copyflo. Wider pages which are capable of yielding an acceptable reproduction when reduced to 11 inches may also be reproduced in this format.

Positions $1 B$ and $2 B$. Single or double pages 11 inches in height can be reproduced full size, larger pages in reduced size.

Position 2A. If the width of two pages does not exceed 11 inches, the material can be reproduced full size. Larger materials will be reduced to the 11 -inch maximum. In filming loose sheet material, doubling the frame length will permit

${ }^{16}$ One lahoratory offers 12 -inch paper but states that the printing surface is "11 inches approximately." 
FIGURE 1

Microfilm Position Chart

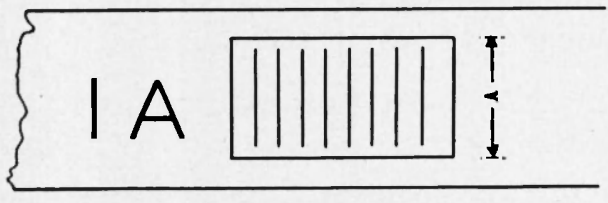

Single Page/Double Frame

(Text parallel to short axis of film)

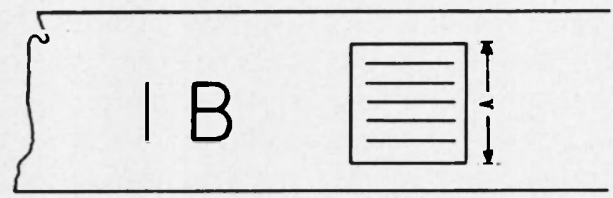

Single Page/Single Frame

(Text parallel to long axis of film)

the filming of four pages per exposure in this format.

\section{Framing and Spacing}

Even at moderate ratios, the reduction in size achieved in microphotography is so great that film space is frequently used carelessly and prodigally. It is not uncommon to see a film of a series of short articles separated from each other by a foot of blank film. If such a film were enlarged ten diameters, the nineteen one-foot spaces would become 190 feet of waste paper which would add considerably to the cost. Excess film used for spacing should be spliced out before printing.

Framing and spacing between frames also should be carefully controlled. Oneeighth inch of excess frame space on each side of 600 frames enlarged twelve diameters would require almost 150 feet of additional paper. In using cameras such as the Recordak or Kodagraph $\mathrm{Mi}$ crofile Models C, D, and E, in which the spacing between frames is controllable, the spacing should be adjusted to a minimum.

\section{Alignment of Images}

Careful alignment of successive images

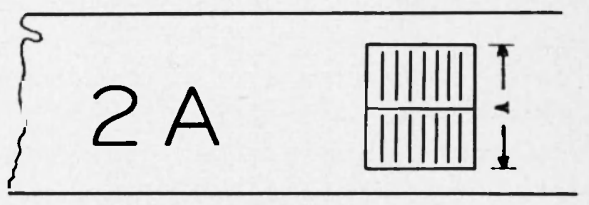

Double Page/Single Frame (Text parallel to short axis of film)

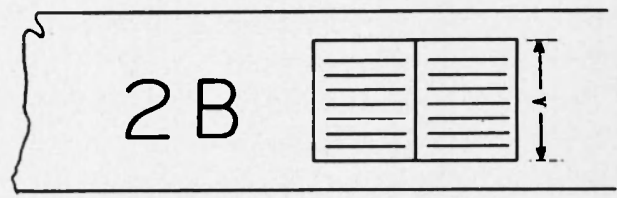

Double Page/Double Frame (Text parallel to long axis of film)

on microfilm will reduce both labor and materials costs. As shown in Figure 2, a microfilm of $3 \times 5$ cards properly aligned can be reproduced on a roll of 5-inch paper, whereas cards filmed without regard to alignment may require 7 - or 8inch paper. It will also be seen that prints of unaligned images will require more labor in cutting and trimming.

\section{Binding Margins}

While lateral control for positioning the projected image on the roll of paper is possible with Copyflo equipment, the best practice for obtaining additional paper area for binding margins is to provide for it in the positioning, spacing, and alignment of images during filming. In photographing large pages from bound volumes in position $1 \mathrm{~A}$, the pages should be offset to the right. Using positions $\mathrm{BB}$ and $2 \mathrm{~B}$, increasing the length of the frame will provide the desired margins. Using position $2 \mathrm{~A}$, the volume can be offset to the right if only a left-hand margin is required. If a folded format is to be used, the magnification of the image can be controlled to provide a margin. A 9-inch image width for the two-page format, when printed on 11inch paper, will provide an additional 
inch on both sides. An 8-inch image width will provide $1 \frac{1}{2}$ inches of margin on each side, and so on.

\section{Enlargement Ratios}

The degree of enlargement obtainable with Copyflo equipment is not adjustable over a continuous range. There are ten fixed magnification steps for $35 \mathrm{~mm}$. film-7, 71/2, 81/2, 9, 91/2, 11, 12, 13, 14 and 15. Additional magnification steps of 17, 18, 19, 22 and 24 may be used for enlarging from $16 \mathrm{~mm}$. microfilm. If documents are to be reproduced to the exact size of the originals, the reduction ratio used in filming must correspond to one of the listed magnifications.

\section{TECHNICAL FACTORS}

\section{Reproduction of Illustrations}

The electrical characteristics of the xerographic process are such that a charge can be held by the selenium plate as a "line" image but cannot be held over large solid areas such as are found in continuous-tone illustrations. For example, if a black area one-inch square is reproduced, only a shadowed outline of the square would appear. The center would be white. Although a method exists whereby solid-tone areas can be "held" in making single-copy reproductions by xerography, this is not possible with present Copyflo equipment. The reproduction of materials which contain significant continuous-tone illustrations such as scientific journals cannot, therefore, be successfully accomplished by this method.

\section{Density}

Copyflo printers are capable of printing from a wide latitude of background densities. For the best results, however, a background density of 1.2 plus or minus 0.2 is desirable. Good contrast between image and background areas is equally important. Because the printing
FIGURE 2

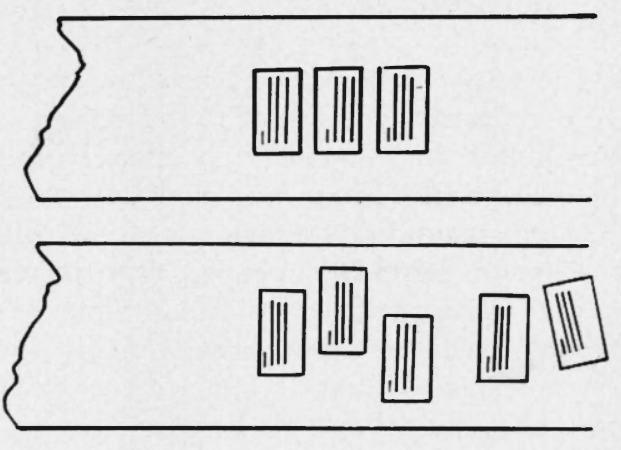

process is a continuous one, abrupt changes in density within the roll of microfilm cannot be compensated for by changes in exposure.

\section{Permanence}

Since the powder image which is fused to the paper is reported to be as permanent as the paper itself, ${ }^{17}$ xerographic enlargements on a high quality rag-stock paper should be as durable as any document ever produced.

\section{ECONOMIC FACTORS}

\section{Equipment and Operating Costs}

Unlike other reproduction methods such as blueprints and diazo, square footage of paper and cost do not stand in a fixed relationship in printing by means of Copyflo. At the present time Copyflo equipment is priced far beyond the reach of all but the largest libraries. The Model 1 machine may be purchased outright for $\$ 52,500$, may be rented by the month for $\$ 1,250$ or may be rented on a "Meter Plan" for $\$ 800$ per month. The monthly rental under the "Meter Plan" entitles the user to only twentyfive hours of machine running time during the month. Additional running time is charged for at a rate of fifty cents per minute up to a maximum monthly ren17 R. M. Schaffert, "Xerography and Xeroprinting,"
Penrose Annual, XILV (1950), 96-99. 
tal of $\$ 2,050$. Machine running time is therefore the principal cost factor in printing by Copyflo. Because the machine running time is always the same regardless of the width of the paper used, prints are significantly cheaper if the full width of 11-inch paper can be used to maximum advantage. The selling price for 1,000 feet of 11 -inch paper prints as given by one commercial firm is only $81 / 2$ per cent greater than for 1,000 feet of $51 / 2$-inch paper prints, even though twice as much paper is used.

To give a specific example of how this can affect costs, let us assume that a Copyflo reproduction is to be made of a book having 1,000 pages $51 / 2$ inches wide and 7 inches high. Five hundred exposures would be required to microfilm this book. If position 2-B were used, full size prints could be made on a roll of paper 7 inches wide. Allowing an extra inch of paper for spacing between frames, each print would measure $7 \times 12$ inches. Five hundred prints would therefore require 500 feet of 7 -inch paper. If position 2-A were used, full size prints could be made on a roll of paper 11 inches wide. Again allowing an extra inch of paper for spacing between frames, each print would measure $8 \times 11$ inches. Five hundred prints would thus require a total of 333 feet of 11-inch paper. Figured at commercial rates, 500 feet of 7 inch paper would cost 41 per cent more than 333 feet of 11-inch paper, even though the total square footage of paper used is virtually identical.

\section{Commercial Sources}

Because of the high costs of Copyflo equipment, libraries which wish to have enlargement prints from microfilm made by this process must turn to one of the commercial laboratories offering this service. At the present time there are twenty-one Copyflo installations in this country at the following locations: Ann Arbor, Michigan, University Microfilms, Inc.; Atlanta, Georgia, Recordak Corporation; Cambridge, Massachusetts, General Microfilm Company; Chicago, Illinois, Xerox Processing Laboratories, division of Haloid-Xerox, Inc. and Recordak Corporation; Dallas, Texas, Recordak Corporation; Denver, Colorado, Dakota Microfilm; Houston, Texas, Southern Microfilm Company; Long Island City, New York, RemingtonRand, Inc.; Los Angeles, California, Recordak Corporation, and Microfilm Company of California; New York City, New York, Xerox Processing Laboratories, division of Haloid-Xerox, Inc. and Recordak Corporation; Redwood City, California, Mark Larwood Company; Saint Louis, Missouri, Recordak Corporation; Saint Paul, Minnesota, Dakota Microfilm; San Francisco, California, Recordak Corporation, Branco's Graphic Arts Service and George Reproductions; Seattle, Washington, Mark Lar-

TABLE I

Price Range of Copyflo Prints from Six Commercial Sources*

\begin{tabular}{c|c|l|l|l}
\hline \hline $\begin{array}{c}\text { PAPER } \\
\text { WIDTH }\end{array}$ & $\begin{array}{c}\text { ORDINARY } \\
\text { SULPHITE BOND }\end{array}$ & $\begin{array}{l}24 \# 100 \% \\
\text { RAG STOCK }\end{array}$ & $\begin{array}{l}90 \# 25 \% \\
\text { RAG STOCK }\end{array}$ & $\begin{array}{l}\text { PAPER OFFSET } \\
\text { MASTER STOCK }\end{array}$ \\
\cline { 2 - 4 } $5^{\prime \prime}$ & $\$ 46.25-69.30$ & $\$ 81.73-$ & $\$ 84.40-$ & \\
$6^{\prime \prime}$ & $\$ 47.30-70.38$ & $\$ 82.66-99.19$ & $\$ 85.33-102.40$ & \\
$81 / 2^{\prime \prime}$ & $\$ 49.05-73.20$ & $\$ 85.00-102.00$ & $\$ 87.67-105.20$ & \\
$9 \prime$ & $\$ 49.40-73.74$ & $\$ 85.46-$ & $\$ 88.13-$ & \\
$10^{\prime \prime}$ & $\$ 50.00-74.88$ & $\$ 86.40-103.68$ & $\$ 89.07-106.88$ & $\$ 100.00-138.88$ \\
$11-12 "$ & $\$ 50.80-76.02$ & $\$ 87.33-104.80$ & $\$ 90.00-108.00$ & \\
\hline
\end{tabular}

* Price per 1,000 feet uncut. 
wood Company; Syracuse, New York, Hall and McChesney, Inc.; Washington, D. C., Recordak Corporation and Remington-Rand, Inc. Other firms have Copyflo machines on order. Information on additional sources of Copyflo prints may be obtained from Haloid-Xerox, Inc., Rochester 3, New York.

\section{Paper Stocks}

Copyflo prints can be supplied on a variety of paper stocks, including 20- and 24-pound white sulphite bonds, 90pound sulphite, 24-pound 100 per cent rag, 90-pound stocks having a rag content of 25, 50, or 100 per cent, 120-pound 100 per cent rag, linen ledger, a translucent vellum 100 per cent rag, and short run paper offset master stock. To make paper offset masters from microfilm negatives, the originals should be filmed under glass in position A-I in a frame area 16 inches long to provide the necessary 15 inches for the length of the master. Successive images should be carefully aligned to minimize registration problems in the offset printing process. Masters thus prepared are not slotted or perforated. Users whose machines have pin bars must perforate or slot the masters to fit their machines.

\section{Costs of Copyflo Prints}

Prices for Copyflo prints obtained from commercial sources show considerable variation. The range for thousandfoot rolls of prints for a few typical sizes from six commercial sources is given in Table I. Cutting charges are in addition to the prices shown. A single cut merely to separate the prints will vary in cost from $\$ 3.75$ to $\$ 5.33$ per thousand prints. A second gang cut to bring the prints to uniform size will cost from $\$ 1.25$ to $\$ 2.67$ additional, per thousand prints. Third and fourth cuts, where required, add still further to the total cost. The minimum charges in effect at some of the laboratories may make the reproduction of small quantities of material prohibitively expensive. Minimum charges of $\$ 15.00$ per order are not unusual.

\section{SUMMARY}

Copyflo equipment has made possible the production of permanent enlarged prints from microfilms on a variety of standard paper stocks at costs which are substantially lower than previous methods. The process is well suited to the reproduction of text and line drawings but does not yield satisfactory copies of continuous-tone illustrations. Other physical, technical, and economic factors place further limits on its utility. Since the largest single cost factor is machine operating time, careful attention to the arrangement, spacing, framing, and alignment of images is necessary if the maximum in efficiency and economy is to be realized. The cost of the equipment is such that most libraries must depend on commercial services. The usefulness of the method in solving documentary reproduction problems can be determined only if its limitations as well as its capabilities are understood.

\section{National Union Catalog of MSS}

The Council on Library Resources has made a grant of $\$ 200,000$ to the Library of Congress to initiate work on a National Union Catalog of Manuscript Collections. The immediate goal of the grant is to bring together consistent descriptions of some twenty-seven thousand known collections of manuscripts in over seventy-five cooperating depositories and to print and sell catalog cards describing each collection. It is the hope of the Council "that this catalog will eventually record all collections of manuscripts held by libraries and archives in the United States." 